\title{
Impact of job Satisfaction on Relationship Between Employee Performance and Human Resource Management Practices Followed by Bharti Airtel Limited Telecommunication with Reference to Moradabad region
}

\author{
Vipin Jain, Chanchal Chawla, Satyendra Arya, Rachit Agarwal, Manoj Agarwal
}

\begin{abstract}
In this research, the goal was to establish a relationship between employees in Bharti Airtel Limited Telecommunications between human resources practice and employee performance. The goal was also to explore the moderating role of job satisfaction in the interaction between human resources activities such as the workforce, compensation, and equity and work efficiency. Staff of Bharti Airtel Limited Communications, Moradabad, Uttar Pradesh, was included in the study population. The sample size is 362 and was selected randomly. 462 employees were furnished with the questionnaires, 362 of which had been collected. The research obtained the following results: an important relationship exists between the work environment and the performance of the employees. There is an important connection between the performance of employees and rewards. The connections between fairness and the performance of employees are significant. The relationship between working conditions and fairness and the performance of employees is affected by job satisfaction. Nevertheless, the relationship between reward and the performance of workers does not affect it. On the basis of the research findings, many practical and theoretical implications have been discussed.
\end{abstract}

Keywords: Employees Performance; Fairness; Job Satisfaction; Reward; Work Environment; Quality of Work.

\section{INTRODUCTION}

Human Resource Management and Planning (HRMP), due to its emphasis on the human element as valuable resources to handle and generating worldwide, is one of the most significant management functions. HRMP includes several sections such as the Planning, Training and Development Department, the Performance and Motivation department and much more. The recruitment and development of human capital is a key component of most organisations. This will

\section{Revised Manuscript Received on October 22, 2019.}

Dr. Vipin Jain, Director and Professor, Teerthanker Mahaveer Institute of Management and Technology (TMIMT), Teerthanker Mahaveer University, Moradabad. Institute of Management and Technology (TMIMT), Teerthanker Mahaveer University, Moradabad.

Dr. Satyendra Arya, Associate Professor, Teerthanker Mahaveer Institute of Management and Technology (TMIMT), Teerthanker Mahaveer University, Moradabad.

Dr. Rachit Agarwal, Director, United Resourcing Services Pvt. Ltd.

Dr. Manoj Agarwal, Associate Professor, Teerthanker Mahaveer Institute of Management and Technology (TMIMT), Teerthanker Mahaveer University, Moradabad
Dr. Chanchal Chawla, Associate Professor, Teerthanker Mahaveer

enable companies to attract and qualify the skills required to maintain their pace with current and future challenges. The objective is to strengthen organizational capacity.

HRs will play a significant role in achieving the Organization's aims and benefit. Management of human resources involves, in brief, maximizing the human element present and planned. The effectiveness, ability, expertise and passion for practice of this human element depend on the effectiveness and performance of the organisation. Management scientists are therefore involved in identifying the values that enable any person in the company to benefit from handling the human resources.

Such structures start with the preparation and recruitment of human resources, training of staff, compensation programs, assessment, and all the human-element negotiations.

\section{REWARDS}

Rewards play an important role in promoting the success of staff in companies. Regulatory agencies benefit greatly from the implementation of the compensation system through a variety of ways that demonstrate the quality of their jobs, such as the concentration of resources and the assessment of their success and their particular expertise. Specific payment schemes, including salaries, wages, incentives etc, are referred to as materiel rewards. Rewards are one of the main factors determining the productivity of employees in businesses and organisations.

Motivation is a key factor in companies and is one of the right strategies for getting employees ' best, be it ethical or content. Motivation, positive or negative, can take many forms Therefore, inspiration can vary from person to person, position to place. Strategies of encouragement have taken several steps; the first is the conventional way of dealing only with material rewards. The next stage, which the School of Human Relations has embraced, centered on ethical and material incentives. The next phase is the current period which incorporates financial and spiritual incentives.

There is a significant role of rewards in the employees' productivity.

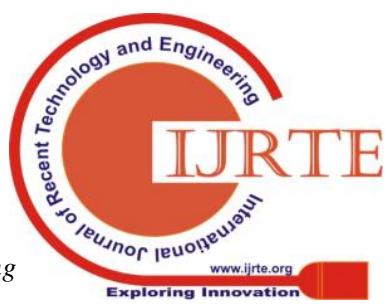




\section{Impact of job Satisfaction on Relationship Between Employee Performance and Human Resource Management Practices Followed by Bharti Airtel Limited Telecommunication with Reference to Moradabad region}

The value of rewards is the need for the individual to realize that their contributions and achievements are so significant. Appreciation of the efforts of others by rewards is necessary to fulfill the fundamental needs of human communication.

\section{Job Satisfaction}

The concept of job satisfaction, as a result of the diversity and differences of opinion that sought to define the concept, was defined by many different definitions. Ginzberg and Herma are among the original interpretations of the idea of job satisfaction in general. It was proposed that three forms of job satisfaction are distinct, such as inner happiness variables that derive from career fulfillment, human perceptions of achieving social success and personal success. Similarly, internal happiness considerations are the perks, wages and friendships. This is not significant, but rather how much this number represents the individual's aspirations according to their values and goals.

\section{PERFORMANCE AND WORK ENVIRONMENT}

Any organization's environment includes internal and external factors, events and organizations (politics, law, social, technical) outside its borders. Such variables might be simplistic, consistent and nuanced. Some important elements include performance, perception, motivation, abilities, attitudes, and learning abilities in the individual organisations.

\section{Performance and Rewards}

Rewards are a component of the administrative function that cannot achieve full goals without any organisation. These are other ways in which the corporation, together with the available resources of organisations, and the experience of the organization's workers in their respective fields, apprecio-politics to their personnel for their exceptional performance and excellent work.

But because of the implementation of an intervention plan or extensive training to increase job performance, the incentives can only achieve the goals of the company. Simply speaking, the training of employees is an element that must be understood by the organization, in order to improve its efficiency and to offer training opportunities to all employees.

\section{Performance and Fairness}

The cornerstone for equality, democracy and civil harmony is preserving dignity to people, and its aim is to protect citizens ' rights and freedoms in forms of discrimination, which limits them. Fairness is intended to provide people with equal rights when their conditions are equal to this situation. In the practice of public functions in the State, and in the employee's entitlement to rewards and promotion, the principle of fairness has different manifestations before law, justice and fairness.

In the exercise of public venues in the state justice means that people are equal in incomes, pensions, rights and duties in the theory of public selection. There seems to be no question that disparities in privileges, wages and promises between different jobs are not consistent with public office fairness, as such equality exists only among those with the same requirements and credentials. There would be nothing to prevent the development, particularly as regards fairness and the rights to access and the benefit from rewards and promotions, of regulatory groups of personnel in accordance with the nature of the functions and the job process.

Employers must redress their employers transparently and credibly; qualified workers must not be stripped of their privileges and all employees are equal in quality because equality is not available when the rights are violated. It is therefore not an empirical fact that we see a steady increase in the number of workers marginalized in organisations, especially if they have no other aid or are supported by people who do not apply. His feeling of injustice in his career is the worst thing he can have at work.

\section{METHODOLOGY}

To complete the study, survey was conducted on a qualitative approach for data collection and used to collect data on the practices of human resources performed by employees of telecommunication sector of Bharti Airtel Limited. Employees from Bharti Airtel Limited Communications, Moradabad, Uttar Pradesh, were included in the study population. The sample size was 362 and was selected randomly.

The framework for the study was as per the figure 1:

\section{Framework:}

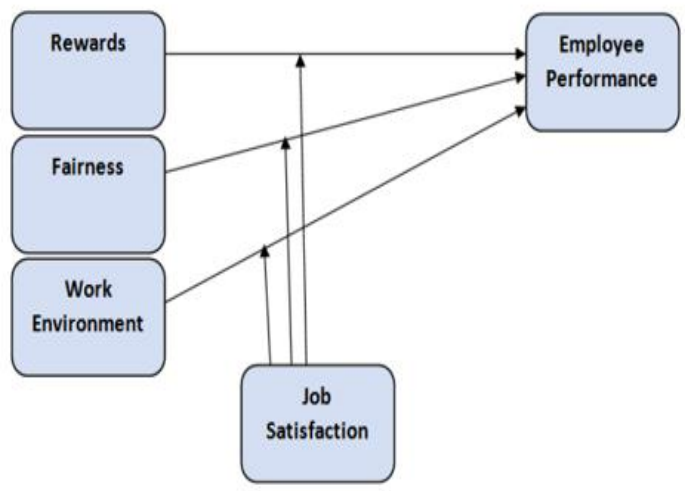

Figure 1: Conceptual Model.

\section{Findings and Results}

\section{Descriptive Statistics}

To illustrate the basic features of the data used in this analysis, we have applied descriptive statistics. The sample and measures are described in simple terms. The mean and standard deviation are shown in Table 1 below. In this study the average was calculated to measure the central trend in the data. At the other side, the default deviation was also determined to represent the rate at which objects vary from the average of the factor in each equation. 


\begin{tabular}{|l|c|c|c|}
\hline \multicolumn{4}{|c|}{ Table l: Descriptive Statistics } \\
\hline Variables of the study & $\mathbf{N}$ & Mean & Std. Deviation \\
\hline Work Environment & 362 & 3.5511 & 0.73619 \\
Reward & 362 & 3.371 & 0.74613 \\
Fairness & 362 & 3.1672 & 0.76933 \\
Job Satisfaction & 362 & 3.3076 & 0.75801 \\
Performance & 362 & 3.3832 & 0.75243 \\
\hline
\end{tabular}

It was shown from Table 1 below that all variables obtained a median lower than the average were used in this analysis. In contrast, the Work Environment has earned the highest average of 3.5511 and the lowest level of the Reward is 3.1672. In addition, the results of the standard deviation are given in Table 1, showing that the Fairness variable is the largest difference to its mean $\mathrm{SD}=.76933$ indicating a high variability in perception of staff to Fairness. In contrast, $\mathrm{SD}=.73619$ was the lowest deviated factor of the Work Environment Variable.

\section{V.ANALYSIS OF RELIABILITY}

Essentially the consistency evaluation was implemented in order, primarily for the reliability of all independent variables (fairness, working environment, reward and job satisfaction, as mods) and the dependent (employees performance), to ensure internal stability of things used in Cronbach's Alpha measure (Cronbach's Alpha, 1951). Of scale consistency Klassen said that the bare minimum acceptable alpha is 0.60 . Nonetheless, under Nunnally 0.70, good measurements are regarded as reliable for items. The greater Cronbach alpha's value is equal to 1.0, Sekaran said. Normally, when reliabilities are less than 0.60 , they are regarded inaccurate and reliability values above 0.70 are deemed reliable and those above 0.80 , are deemed to be good. All the independent variables and dependent variable, as discussed in Table 2, ranged from 0.809 to 0.871 . In addition, the workplace environment analysis was 0.854 , a reward factor of 0.839 , the next is the fairness factor which gained 0.809 . In contrast, job satisfaction which is the moderator element has attained .846 . In contrast, employee performance, the dependent factor attained the highest value of .871 .

\begin{tabular}{|c|l|c|c|c|}
\hline \multicolumn{5}{|c|}{ Table 2: Reliability Analysis } \\
\hline \multicolumn{1}{|c|}{ Factors } & $\begin{array}{c}\text { Cronbach's } \\
\text { Alpha }\end{array}$ & $\begin{array}{c}\text { N } \\
\text { of Items }\end{array}$ & $\begin{array}{c}\text { Items } \\
\text { deleted }\end{array}$ \\
\hline 1 & Work Environment & 0.854 & 5 & - \\
2 & Reward & 0.839 & 5 & - \\
3 & Fairness & 0.809 & 5 & - \\
4 & Job Satisfaction & 0.846 & 5 & - \\
5 & Employee Performance & 0.871 & 5 & - \\
\hline
\end{tabular}

In conclusion, the parameter is considered accurate by five elements for each variable in all independent variables and dependent variables (Table 3).

\section{Multiple Regression Analysis}

Extension of simple linear regression is also known as Multiple Regression. When we want to estimate the values of factors which are dependent on two or more factors, we use multiple regression. The predictor investigator is referred to as the dependent variable (Employee's performance). While the researcher uses variables to predict the value of the dependent variable, they are referred to as independent variables (working environment, reward, fairness and job satisfaction).

\section{Model Summary}

When running regression or classification models, a model summary is automatically created. R: By attaining the value of $\mathrm{R}=83.6 \%$, there is significant relation between all the independent and dependent factors in the model. R-squared is a numerical calculation of the closeness of the results to the right regression line. The result of the model synthesis table is the model description and the figures match together. It is shown that the R2 of the system modified is 0.695 with $\mathrm{R} 2=0.699$, that being 69.9 percent of the data fluctuation is clarified by linear regression (Table 4 ).

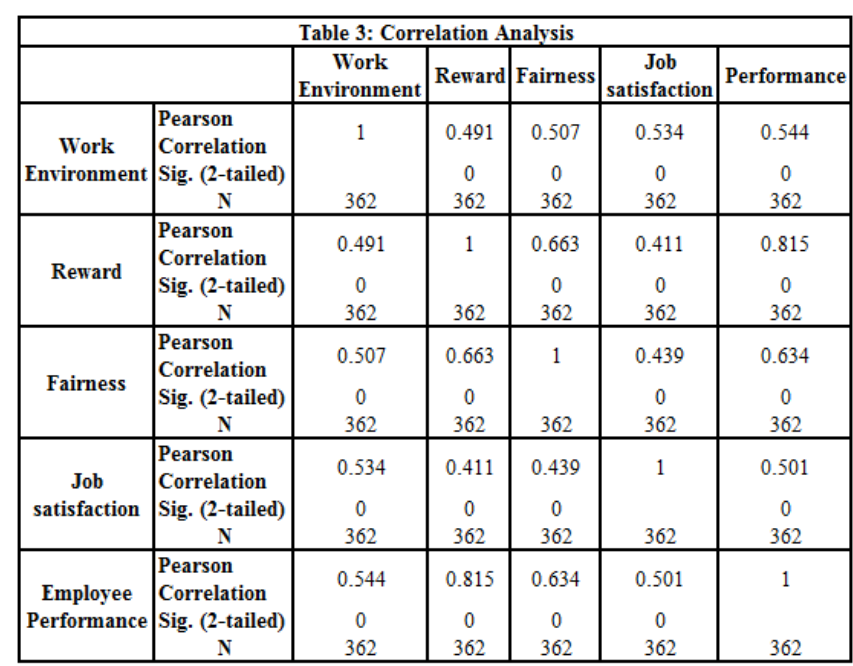

\section{ANOVA Analysis}

The test is highly significant with 361 degree of freedom and $\mathrm{F}=199.319$, and thus it can be assumed with all variables and factors applied in the model of the paper that there exists a linear relationship in all variables. Table 5 below signifies it:

\begin{tabular}{|c|l|c|c|c|c|c|}
\hline \multicolumn{7}{|c|}{ Table 5: ANOVA } \\
\hline & Model & Sum of Squares & Df & Mean Square & F & Sig. \\
\hline \multirow{3}{*}{1} & Regression & 103.227 & 3 & 34.409 & 199.319 & 0 \\
& Residual & 44.539 & 358 & 0.173 & & \\
\cline { 2 - 7 } & Total & 147.766 & 361 & & & \\
\hline
\end{tabular}

\section{Coefficients Analysis}

H1: There is an important correlation among employees' performance and work environment. The results of regression analyses indicate that the work environment factor has a significant impact on the performance of employees $(\beta=$ 0.162 ; and $\mathrm{P}=0.000$ ) which is revealed in Table 6 below. 


\section{Impact of job Satisfaction on Relationship Between Employee Performance and Human Resource Management Practices Followed by Bharti Airtel Limited Telecommunication with Reference to Moradabad region}

\begin{tabular}{|c|l|c|c|c|c|}
\hline \multicolumn{6}{|c|}{ Table 6: Coefficients } \\
\hline \multirow{2}{*}{\multicolumn{2}{|c|}{ Nodel }} & \multicolumn{2}{|c|}{ Unstandardized Coefficients } & Standardized Coefficients & \multirow{2}{*}{ Sig. } \\
\cline { 2 - 5 } & B & Std. Error & Beta & \\
\hline 1 & (Constant) & 0.197 & 0.143 & & 0.169 \\
& Work enriromment & 0.166 & 0.042 & 0.162 & 0 \\
& Reerard & 0.664 & 0.047 & 0.659 & 0 \\
& Fairness & 0.113 & 0.046 & 0.116 & 0.016 \\
\hline
\end{tabular}

$\mathrm{H} 2$ : There is an important correlation among employees' performance and reward. Table 6 below shows that the reward factor has a significant impact on employee performance $(\beta=0.659$; and $\mathrm{P}$ value $=0.000)$ as a consequence of regression analysis.

H3: There is an important correlation among employee performance and fairness. As shown in Table 6 below, the results of regression analysis show that fairness is a significant factor in the performance of employees $(\beta=0.116$ and $\mathrm{P}$-value $=0.016$ ).

\section{Regression Analysis with Moderator}

The regression analysis was re-applied by including the moderator to the analysis that is job satisfaction in order to find the significant potential of moderator and independent performance variables.

\section{Model Summary}

The authors have again done the regression analysis by including the moderator parameter that is job satisfaction, in this section. When using regression modeling and classification models, a model description is generated automatically. R, Multiple coefficient of interrelation between all the models independent, the variable moderator and the variable Dependent, showing an important correlation with $\mathrm{R}=89.1$ per cent. $\mathrm{R}$-squared is a linear extrapolation of the close proximity of the data to the right regression coefficient. The outcome of the model summary table shows the model synthesis and the statistical complement. Findings shows that the adjusted R2 of the model is $79.1 \%$ with $\mathrm{R} 2=$ 0.794 which means that the linear regression explain $79.4 \%$ of the variance in the data.

Comparing the model summary result with the model summary without modeler shows that, by getting $\mathrm{R}=89.1$ percent, the model's fitness exceeds the model without the modeler and by getting R-Squared=79.4 percent, the model has a significant relationship.

There is possibly important moderation among work environment, reward fairness and job satisfaction on employee performance (Table 7).

\begin{tabular}{|c|c|c|c|c|}
\hline \multicolumn{5}{|c|}{ Table 7: Model Summary } \\
\hline Model & R & R Square & Adjusted R Square & Std. Error of the Estimate \\
\hline 1 & 0.89 & 0.794 & 0.791 & 0.34414 \\
\hline
\end{tabular}

The test is extremely significant at $\mathrm{F}=247.678$, and 361 degrees of freedom, so we can assume that there is a linear relationship between each of the variables used in this study model, indeed the job satisfaction as moderating variable. The table 8 below signifies it:

\begin{tabular}{|c|c|c|c|c|c|c|}
\hline \multicolumn{7}{|c|}{ Table 8: ANOVA } \\
\hline & Model & Sum of Squares & Df & Mean Square & F & Sig. \\
\hline 1 & Regression & 117.33 & 4 & 29.332 & 247.678 & 0.0006 \\
& Residual & 30.436 & 257 & 0.118 & & \\
\hline & Total & 147.766 & 261 & & & \\
\hline
\end{tabular}

aDependent Varrable: Employee Performance.

\section{bPredictors: (Constant), Job Satisfaction_Employee Performance, Work environment_Job Satisfaction, Fa armes___ob Satusfaction, Rewards__ob Satisfaction.}

For model 1 without relevant moderator word, $F(3,258)=$ $199.319, \mathrm{p}<0.01$. The value of model two with moderator is $\mathrm{F}$ $(4,257)=247.678, p<0.01$. Generally, the findings indicate that both models one and two are important, but the version with the moderator included is smaller than model 1 without the moderator involved.

Coefficients Analysis Including the Moderator

The goal was to determine whether or not the relation between the independent variables (work environment, compensation, and fairness) and the dependent variable (employee performance) depends on the moderator variable (employment satisfaction) for which multiple regression analysis was applied. The first variables were based and combined together to reflect the interplay between (working environment, fairness and rewards) and job satisfaction.

The results revealed that, based on job satisfaction, the effect of the working environment and fairness has more control on employees' performance. Yet, according to job satisfaction, the reward does not have a significant impact on employee performance.

The standardized B and sig. values that emerged from this analysis are presented in Table 9 below.

\begin{tabular}{|c|c|c|c|c|}
\hline \multicolumn{5}{|c|}{ Table 9: Coefficients } \\
\hline \multirow{2}{*}{ Model } & \multicolumn{2}{|c|}{ Unstandardized Coefficients } & \multirow{2}{*}{\begin{tabular}{|c|} 
Standardized Coefficients \\
Beta \\
\end{tabular}} & \multirow{2}{*}{ Sig. } \\
\hline & B & Std. Error & & \\
\hline 1 (Constant) & 1.917 & 0.065 & & 0 \\
\hline $\begin{array}{l}\text { Work environment_Job } \\
\text { satisfaction }\end{array}$ & -0.072 & 0.01 & -0.414 & 0 \\
\hline Reward__ob satisfaction & -0.012 & 0.015 & 0.059 & 0.43 \\
\hline Fairness_Job satisfaction & -0.029 & 0.011 & -0.162 & 0.01 \\
\hline $\begin{array}{l}\text { Job satisfaction_Employee } \\
\text { Performance }\end{array}$ & 0.242 & 0.015 & 0.4154 & 0 \\
\hline
\end{tabular}


Among this instance, the value of the term "reward and job satisfaction" is greater than 0.05 and thus has no significance. With instance from, the researchers would rather assume that there is no proof that job satisfaction at work reduces or influences the effect of rewards on results. On the other side, the significance value that relates to job satisfaction and working environment is 0.000 which is lower than 0.05 and hence is significant. Meanwhile the significance value that relates to job satisfaction and fairness is 0.010 that is lower than 0.05 and is therefore bound to be significant which is also signified by table 9. Henceforth, job satisfaction highly moderates the effect of work environment, fairness on employee's performance but not the reward.

Findings and Discussions with Hypotheses Testing

H1: Among working environment and the performance of employees there exists a significant correlation. A value under 0.05 is a positive relation between the two variables in the regression analysis test, as per the Westfall. Table 9 above therefore indicates a positive relationship between the work environment and the performance of employees in Bharti Airtel Limited Telecommunication which attained the significance value of less than $0.05(\mathrm{P}=0.000)$. This results in the fact that the relationship between the workforce and worker productivity is of significant importance.

A value above -0.404 would indicate that the corresponding independent variable in the work environment is negatively linked to the workplace performance. It is surprising that employee performance in a basic working environment is better or less good.

This finding is in line with the findings by Diamantidis and Chatzoglou that there is an important relationship between working environment and employees' performance that means that the employee's performance results will be higher if he is satisfied with his working environment. Omolo also found that the company's performance is heavily influenced by the work environment, as a good workplace environment can improve employee performance.

$\mathrm{H} 2$ : There exists an important correlation between employees' performance and rewards. As stated by Hochber, there is always a positive correlation among the variables if they attain P-value which is lower than 0.01, 0.05 and 0.10 In fact, Westfall stated that, the significance value lower than 0.05 in regression analysis test always means that there is positively high correlation between variables. Table 9 above therefore states that no positive correlation exists among employees; performance and rewards in Bharti Airtel Limited as it has attained $\mathrm{P}=0.430$ which is greater than 0.05 .

Sajuyigbe et al. found that the dimension of reward has a substantial impact on employee performance. Such results show that rewards, quality incentives and congratulations, as well as appreciation and praise, allow management organisations to work effectively and efficiently and inspire workers. In fact, the expectations of workers about the quality of service restoration have a significant impact. Jenkins et.al reported that higher income increases the amount of work carried out by workers.
Those finding from previous studies, goes equally with the findings of this study in model one where there is no moderator.

In Model two with the moderator included in the study, the results show that job satisfaction has no effect on the reward for the workers in Bharti Airtel Limited in Moradabad. Inclusion of job satisfaction as proxy for the interaction between the reward and the quality of employees. The research showed that the correlation between reward and worker performance has improved little in terms of job satisfaction.

H3: Hochberg said that there is an essential link between equality and employee efficiency, since the $\mathrm{P}$ value is less than, 0.01., 0.05 and 0.10 there are two variables. Goodman (1999) furthermore indicated that in the regression analysis test the importance value that is less than 0.05 means that the two variables have a favorable relationship. In accordance with that of Table 9 above, Fairness and employee performance in Moradabad have had a positive relationship as a result of the significance factor of $(\mathrm{P}=0.010)$ less than 0.05 . This conclusion is also focused on observations from previous studies such as Aryee and others that fairness is connected to role success and the associated relational facilitation and work commitment dimensions. In contrast, Janssen said managers who experience fairness in terms of effort-reward perform well.

The beta value of the working environment of- 0.162 suggests that the associated independent factor that has a workplace environment is adversely related to the quality of the employees. Negative beta value usually means negative correlation. It is relevant, but negative.

H4: Job satisfaction curbs the correlation among working environment and employees' performance. If the two variables attain $\mathrm{P}$-values less than $0.01,0.05$ and 0.10 , than there is a positive significant correlation between them, as stated by Hotchberg. Westfall also said that in the regression analysis there is a positive relationship between the two variables, leading to the significance factor which is less than 0.05. In Table 9, the connection between the working environment and the performance of the employee is moderated by work satisfaction because the value of (0.000) is significant. As a result, the researchers concluded that the relationship between employment and worker productivity by the public organization in Moradabad has a modest effect on job satisfaction.

H5: Job satisfaction curbs the correlation among employees' performance and rewards. Table 9 showed that there was no moderate impact on job satisfaction between reward and employee performance in Moradabad public organization because the employee had a significant value of $(\mathrm{P}=0.430)$. The researcher therefore conclude that the reward and employee performance in the Moradabad public organization do not have a moderate effect on job satisfaction. Hochberg said, as the $\mathrm{P}$ value, less than $0.01,0.05$, and 0.10 are obtained, there is a correlation of appositive importance between two different variables. 


\section{Impact of job Satisfaction on Relationship Between Employee Performance and Human Resource Management Practices Followed by Bharti Airtel Limited Telecommunication with Reference to Moradabad region}

Westfall also said that the meaningful value of less than 0.05 in the regression analysis experiment means that the two variables have a positive relationship.

\section{CONCLUSION}

This paper discusses the results based on research issues, which indicate that job satisfaction can play an important role in working environment, fairness and employee performance relations. Nonetheless, job satisfaction in Moradabad, the moderator, does not have a significant effect on the relationship between employee performance and reward. In general, the environment, reward and fairness of work must be established strategically to enhance employee performance. The causes of misunderstanding of the working environment, reward and fairness on the other hand, have an adverse effect on employee performance. The findings show a negative relationship between the working environment and the outcomes of the workers, which means that employees with a bad workspace tend to perform better. Compared to previous studies in the field of work environment and employee performance, this report on the researchers ' best knowledge is different.

\section{REFERENCES}

1. Aryee S, Chen ZX, Budhwar PS (2004) Exchange fairness and employee performance: An examination of the relationship between organizational politics and procedural justice. Organizational behavior and human decision processes 94: 1-14.

2. Babakus E, Yavas U, Karatepe OM, Avci T (2003) The effect of management commitment to service quality on employees' affective and performance outcomes. Journal of the Academy of marketing Science 31: 272-286.

3. Dessler G (2015) Human Resource Management, Person Education Limited, Essex, England.

4. Diamantidis AD, Chatzoglou P (2019) Factors affecting employee performance: an empirical approach. International Journal of Productivity and Performance Management 68: 171-193.

5. Ghaffari S, Shah I, Burgoyne SJ, Nazri M (2017) The Influence of Motivation on Job Performance: A Case Study at Universiti Teknologi Malaysia. Australian Journal of Basic and Applied Sciences 11: 92-99.

6. Ginzberg E, Ginsburg SW, Axelrad S, Herma JL (1951) Occupational choice. New York.

7. Goodman SN (1999) Toward evidence-based medical statistics. 1: The $\mathrm{P}$ value fallacy. Annals of internal medicine 130: 995-1004.

8. Hochberg Y (1988) A sharper Bonferroni procedure for multiple tests of significance. Biometrika 75: 800-802.

9. Ismajli N, Zekiri J, Qosja E, Krasniqi I (2015) The Importance of Motivation Factors on Employee Performance in Kosovo Municipalities. Journal of Public Administration and Governance 5: 23-39.

10. Jain S, Ahuja SK (2019) Impact of Human Capital Management Practices on Employee Job Performance.

11. Janssen $\mathrm{O}$ (2001) Fairness perceptions as a moderator in the curvilinear relationships between job demands, and job performance and job satisfaction. Academy of management journal 44: 1039-50.

12. Jenkins GD, Mitra A, Gupta N, Shaw JD (1998) Are financial incentives related to performance? A meta-analytic review of empirical research. Journal of applied psychology 83: 777.

13. Klassen PT (2003) New TTI instrument reliability studies. Target Training International.

14. Masud H, Daud WNW (2019) Human Resource Management Practices and Organisational Commitment: Research Methods, Issues, and Future Directions.

15. Mira M, Odeh K (2019) The mediating role of authentic leadership between the relationship of employee training and employee performance. Management Science Letters 9: 381-88.

16. Nunnally JC (1978) Psychometric theory (2ndedn). New York, NY: McGraw-Hill.
17. Omolo PA (2015) Effect of motivation on employee performance of commercial banks in Kenya: A case study of Kenya Commercial Bank in Migori County. International journal of human resource studies 5: 87-103.

18. Rai A, Ghosh P, Chauhan R, Singh R (2018) Improving in-role and extra-role performances with rewards and recognition. Management Research Review 41: 902-19.

19. Sajuyigbe AS, Olaoye BO, Adeyemi MA (2013) Impact of Reward on Employees Performance in a Selected Manufacturing Companies in Ibadan, Oyo State, Nigeria. International Journal of Arts and Commerce 2.

20. Sekaran U (2003) Towards a guide for novice research on research methodology: Review and proposed methods. Journal of Cases of Information Technology 8: 24-35.

21. Shapoval V (2019) Organizational injustice and emotional labor of hotel front-line employees. International Journal of Hospitality Management 78: 112-21.

22. Westfall PH, Young SS (1993) Resampling-based multiple testing: Examples and methods for p-value adjustment pp: 360 . 